\title{
Measuring the Level of Integrated Reporting Alignment with the $<\mathrm{IR}>$ Framework
}

\author{
Arcangelo Marrone ${ }^{1} \&$ Lara Oliva $^{1}$ \\ ${ }^{1}$ Department of Economics and Management, University LUM Jean Monnet, Italy \\ Correspondence: Arcangelo Marrone, Department of Economics and Management, University LUM Jean Monnet, \\ Casamassima (BA), Italy. E-mail: marrone@lum.it
}

Received: September 17, 2019

Accepted: October 15, 2019

Online Published: November 10, 2019

doi:10.5539/ijbm.v14n12p110

URL: https://doi.org/10.5539/ijbm.v14n12p110

\begin{abstract}
The growing attention to social, environmental and governance issues has increased the pressure on companies to disclose information that goes beyond the financial aspects. In this scenario, integrated reporting (IR), represents a tool able to bridge the information gap, through a focus on the financial and non-financial aspects, on the existing interconnections between the different business dynamics and on the ability of the company to create value in the short, medium and long term. Several aspects of integrated reporting have been studied in the academic field. However, no study has investigated the level of alignment of integrated reports with the $<\mathrm{IR}>$ framework. This study aims to fill this gap, first of all developing an adequate measure to assess the level of compliance with the $<\mathrm{IR}>$ framework and secondly investigating some determinants of the alignment level. The results show first of all, on average, a high level of compliance of the integrated reports analysed with the $<$ IR $>$ framework and, secondly, they show a positive and significant impact of the firm size and of the industry environmental sensitivity on the level of alignment. This is the first study that investigates the determinants of the level of alignment of the integrated reports with the $<\mathrm{IR}>$ framework.
\end{abstract}

Keywords: integrated reporting, compliance, IIRC, disclosure

\section{Introduction}

The growing attention to social, environmental and governance issues has increased the pressure on companies to disclose information that goes beyond the financial aspects (Frias-Aceituno et al., 2014; Lassini et al., 2016). Considering that financial statements are not able to show the value of corporate intangibles, investors, in order to better evaluate their investment decisions, increasingly need information on the ability of companies to create value over time (Wyatt, 2008; Cohen et al. 2012; IIRC 2017a). In recent years, the business models developed by companies are increasingly based on a trade-off between different capital components, which together create value (Simnett \& Huggins, 2015; Coulson et al., 2015; Albertini, 2019).

In this scenario, integrated reporting (IR), developed by the International Integrated Reporting Council (IIRC), represents a tool able to bridge the information gap, through a focus on the financial and non-financial aspects, on the existing interconnections between the different business dynamics and on the ability of the company to create value in the short, medium and long term (IIRC, 2017a; b). The birth of this reporting tool is dated 2013, the year in which the IIRC published the International $<$ IR> Framework (IIRC, 2013), which defines an integrated report as "a concise communication about how an organisation's strategy, governance, performance and prospects, in the context of its external environment, lead to the creation of value over a short, medium and long term" (IIRC 2013, p7). The central idea of this framework is that companies must include in the integrated report information on all the resources used and on all the results obtained. Therefore, the $<\mathrm{IR}>$ framework revolves around the concept of the capitals that represent the inputs and the outcomes of the business activity. Specifically, the IIRC has identified six different types of capital: financial, manufactured, intellectual, human, social and relationship, and natural (IIRC 2013). Furthermore, the framework provides for the disclosure of information relating to governance, social and environmental issues, corporate strategy, risks and opportunities (IIRC 2013).

The adoption of the integrated reporting guarantees numerous benefits to the companies (Vitolla et al., 2018). However, it is not clear whether these benefits are connected to the simple dissemination of an integrated report or to the preparation of the document according to the guiding principles and the contents dictated by the IIRC. 
In fact, compliance with the framework could allow content standardization able to favor the reading and understanding of integrated reports by investors and all stakeholders. Moreover, a greater alignment allows a comparison between the integrated reports of different companies and, therefore, helps investors and all stakeholders to fully understand the different business realities. Therefore, the aspect relating to compliance is particularly important and differs from the aspects connected to the adoption of this instrument or to the amount of information contained in the integrated report. However, despite the relevance of the theme, the level of alignment of integrated reports with the $<\mathrm{IR}>$ framework appears to be unexplored in the literature. This study, therefore, aims to fill this gap, first of all developing an adequate measure to assess the level of compliance of the integrated reports with the $<\mathrm{IR}>$ framework and secondly investigating some determinants of the alignment level. In this perspective, it is important to analyse the antecedents of the level of alignment since these could be different from those of the adoption or the extent of information contained in the integrated reports.

The remainder of this article is organized as follows. The following section analyses the background of this study. Section 3 presents the research hypotheses while section 4 describes the methodology. Section 5 and Section 6 present and discuss the results. Finally, the last section draws conclusions.

\section{Background}

\section{$2.1<I R>$ Framework and Alignment}

IIRC defines an integrated report as "a concise communication about how an organization's strategy, governance, performance and prospects, in the context of its external environment, lead to the creation of value over the short, medium and long term" (IIRC, 2013). The recipients of this new disclosure tool are mainly investors. However, it represents a means to provide financial and non-financial information to other types of stakeholders such as customers, suppliers, employees, governments and community. Therefore, the integrated report is not a document resulting from the simple sum of financial and non-financial information, but must also specify the existing interconnections between them, so as to make clear to the recipients the way in which the company creates value in the short, medium and long term (Vitolla et al., 2019a).

The framework developed by the IIRC identifies the general principles, the requirements to be observed in the preparation of the report and the process to be followed for the drafting. However, it does not define which KPIs or measurement methods to use. In this sense, companies that opt for the publication of this new disclosure tool have a wide freedom to choose which indicators to include in their report. Therefore, in this perspective, the IIRC provides guidelines on how the integrated report should be understood without however imposing precise constraints. This approach was preferred to facilitate adaptation to the laws in force in the various countries and to encourage voluntary adoption (Del Sordo et al., 2018).

The $<$ IR $>$ Framework was therefore designed to offer a balance between flexibility and prescription. It provides the fundamental concepts, guiding principles and content elements that should be present in an integrated report. In concrete terms, therefore, it represents an "open space" to be filled in a meaningful and reliable way to communicate the process of creating the value of the company (Busco et al., 2014).

The $<\mathrm{IR}>$ framework for the preparation of the integrated report describes fundamental concepts, guiding principles and content elements.

It identifies two fundamental concepts: the value creation process and the capitals. The value is not only the result of the organization itself and of its internal generative capacity, but it is closely connected to: external influences, relations with stakeholders and interaction of different sources. Therefore, the integrated report must provide information on the external environment, on the resources used by the organization and on the ways in which the organization relates with stakeholders in order to create value not only in the short term, but also in the medium and long term. The value creation process is developed through the business model, considered by the $<\mathrm{IR}>$ framework as the heart of the organization. The resources used by companies are identified by the $<\mathrm{IR}>$ framework as capitals. In fact, according to the $<\mathrm{IR}>$ framework, for the creation of value, organizations make use of six capitals that can be divided into: financial capital, manufactured capital, intellectual capital, human. capital, social and relationship capital and natural capital (IIRC, 2013). Therefore, in light of this, greater attention to intangibles is an important aspect of integrated reporting (Melloni, 2015; Vitolla et al., 2019b).

The $<\mathrm{IR}>$ Framework also outlines a series of guiding principles on which the elaboration of the integrated report must be based. The guiding principles identified by the IIRC are: strategic focus and future orientation, connectivity of information, stakeholder relationships, materiality, conciseness, reliability and completeness, consistency and comparability (IIRC, 2013).

Finally, the content elements are eight and are developed as a question. They are related to each other, are not 
mutually exclusive and are not described in a specific order as they are not intended to provide a standard structure. The first element is represented by the organizational overview and external environment. In this regard, the $<\mathrm{IR}>$ framework provides for the insertion of information relating to aspects such as the mission, vision, culture and corporate values, the internal structure, the main activities performed, the markets in which the company operates and the competitors (IIRC, 2013). Organizations should also describe how these elements can contribute to value creation. The second element relates to governance. Organizations must provide information on aspects such as the leadership structure and the board of directors and indicate how these elements foster value creation (IIRC, 2013). The third element concerns the business model. In this regard, companies must provide information about the methods of transforming inputs into outputs with a view to creating value. Therefore, according to the $<\mathrm{IR}>$ framework, an integrated report should include information about the inputs, business activities, outputs and outcomes (IIRC, 2013). The fourth element refers to risks and opportunities. In this regard, companies should provide information on how risks and opportunities can affect the organization's ability to create value. The fifth element relates to the strategy and resource allocation. In this regard, organizations should provide information about the strategic objectives, the methods of achievement, the strategies to be adopted and the sources of competitive advantage (IIRC, 2013). A further element identified by the IIRC concerns performance. In this regard, companies should provide information about the results obtained and the objectives achieved (IIRC, 2013). The seventh element is related to the outlook. Companies should provide forecasts on the external and internal environment and information on the challenges and uncertainties that could arise in the future and on how to manage them (IIRC, 2013). The last element relates to the basis of preparation and presentation. In this regard, organizations must describe how to choose the information to be included in the report. In this perspective, therefore, organizations must provide information about materiality determination processes, reporting boundaries and significant frameworks and methods used to quantify or evaluate material matters (IIRC, 2013).

An integrated report drawn up in compliance with the $<\mathrm{IR}>$ framework and aligned with it, following the guiding principles, includes within it information relating to both the fundamental concepts and the content elements identified by the IIRC.

\subsection{Measuring Integrated Reporting}

Although the integrated reporting represents a relatively new topic, the researchers have already explored several areas of this theme (Vitolla et al., 2019c). Numerous studies have analysed the determinants (e.g. Jensen \& Berg, 2012; Frías-Aceituno et al., 2014; Vitolla et al., 2019d) and the effects of integrated reporting (e.g. Lee \& Yeo, 2016; Barth et al., 2017; Vitolla \& Raimo, 2018; Vitolla et al., 2019e).

Some of these studies have analysed the determinants and effects of the simple adoption of this reporting tool (Frías-Aceituno et al., 2013a; 2013b; 2014) while others have gone further by studying aspects such as the quality (Ahmed Haji \& Anifowose, 2016 ; Pistoni et al., 2018; Bavagnoli et al., 2018; Vitolla et al., 2019a; Pavlopoulos et al., 2019), the readability of the integrated reports (Velte, 2018), the amount of information contained in the integrated reports (Ahmed Haji \& Anifowose, 2016) and the materiality disclosure quality (Gerwanski et al., 2019).

The studies relating to the adoption have analysed the factors that can influence the choice of companies to publish an integrated report and the effects related to the dissemination of this reporting tool. The quality of the integrated reporting, instead, represents a concept that goes beyond the simple adoption (Vitolla et al., 2019a). A first integrated reporting quality measure was developed by Pistoni et al. (2018). The concept of quality developed by the authors covers four different aspects: background; content; form; assurance and reliability. The first element evaluates the title of the report and the presence of an introduction able to provide information about the objectives of the integrated report, the reasons that favoured the adoption, the process managers, the recipients, the commitment from CEO and the compliance with international reporting standards. The second element instead evaluates the level of detail of the information provided within the report. The third element analyses accessibility, readability and clarity and the conciseness of the integrated report. Finally, the fourth element assesses the presence of internal or external assurance and the presence of prizes or awards received by the company for its integrated report. Bavagnoli et al. (2018), in a study on the determinants of integrated reporting quality, used only the content area of the measurement model developed by Pistoni et al. (2018). Another quality measure of the integrated reporting quality is that developed by Pavlopoulos et al. (2019). This quality measure consists of all nine content elements in the King III report and the King III code that are confirmed by the $<\mathrm{IR}>$ framework. These content elements are: ethical leadership and corporate citizenship; boards and directors; audit committees; governance of risk; governance of information technology; compliance with laws, codes, rules and standards; internal audit; governing stakeholder relationships; and integrated 
reporting and disclosure. Finally, Barth et al. (2017) built their proxy for integrated reporting quality from the scores underlying the annual EY Excellence in Integrated Reporting Awards.

Velte (2018) has instead analysed the readability of the integrated reports through the Flesch Reading Ease. The author has identified seven different scores linked to specific limits of the index from 0 to 100 . The readability level of an integrated report therefore ranges from "very difficult to read" to "very easy to read".

Ahmed Haji \& Anifowose (2016) studied the determinants of the quality and extent of information contained in the integrated reports. To measure the extent of information contained in the reports, the authors first identified a list of items based on the guiding principles of the IIRC and then assigned a score of 1 in the case of the presence of a single item and a score of 0 in the case of the absence. To measure integrated reporting quality, the authors have instead used a scale from 0 to 3 that considers respectively the presence of general qualitative, specific and detailed information.

Finally, Gerwanski et al. (2019) measured materiality disclosure quality in integrated reporting. The authors identified seven scoring components: materiality section, identification process, description of material aspects, time horizon, materiality matrix, risks and opportunities, and mitigation actions. Materiality matrix and risks and opportunities take a score of 1 in case of presence and 0 in case of absence. The other elements instead take a score that ranges from 0 to 2 in relation to the level of detail of the information.

Therefore, although several aspects of integrated reporting have been studied in addition to the simple adoption of this tool, the absence of contributions aimed at analysing the level of compliance with the framework developed by the IIRC is evident. This study aims to bridge this gap first of all developing an adequate measure to assess the level of compliance of the integrated reports with the $<\mathrm{IR}>$ framework and secondly investigating some determinants of the alignment level.

\section{Hypotheses Development}

The analysis of the alignment of the integrated reports with the $<\mathrm{IR}>$ framework is still an unexplored topic. While a generally accepted methodology for measuring the level of compliance is still lacking in literature and in practice, a greater effort is needed to identify the determinants of the alignment of integrated reports with the principles dictated by the IIRC. This study therefore focuses on two main aspects that can explain the tendency of companies to align their integrated report with what is expected by the IIRC. Specifically, this study focuses on firm size and on the firm environmental impact.

Several contributions in the literature highlight a positive impact of the firm size on non-financial disclosure (Khan, 2010; Frías-Aceituno et al., 2014; Andrikopoulos et al., 2014; Sharif \& Rashid, 2014; Bhasin et al., 2015; Sierra-García et al., 2015; Abdullah et al., 2015). Legitimacy theory, in its perspective concerning public pressure, highlights the possibility of government interference in business activity for companies that do not respect the social contract (Reverte, 2009). Watts \& Zimmerman (1986) highlight that larger companies are subject to greater public control. They emphasize that large companies have greater visibility and are therefore subject to greater pressure from stakeholders (Dowling \& Pfeffer, 1975). Large companies have greater impacts on the communities in which they operate and therefore generally have a greater number of stakeholders and receive more pressure (Hackston \& Milne, 1996; Knox et al., 2006). Therefore, in this perspective, voluntary disclosure represents a means to reduce pressure from stakeholders, avoid government interference in business activity and reduce political costs (Ness \& Mirza, 1991; Gray et al., 1995; Adams et al., 1998; Clarke \& Gibson-Sweet, 1999). In the context of integrated reporting, greater alignment with the $<\mathrm{IR}>$ framework could represent an opportunity for companies to meet the needs of stakeholders, reduce pressures and avoid government interference in business activity. In fact, a greater alignment with the $<\mathrm{IR}>$ framework allows a greater standardization of contents capable of favouring the reading and understanding of integrated reports by stakeholders. Moreover, a greater alignment with the provisions of the IIRC allows a comparison between the integrated reports of different companies and, therefore, helps stakeholders to fully understand the business dynamics. The greater knowledge of the internal dynamics of the company inevitably leads to a reduction of pressures and the possibility of interference by the government, which represent particularly relevant aspects for large companies. Therefore, in light of this, we introduce the following hypothesis:

\section{H1: Firm size is positively associated with integrated reporting alignment with the $\langle I R>$ framework}

In addition to the firm size, the existing literature shows that the sector to which the company belongs influences non-financial disclosure (Gray et al., 1995; Cowen et al., 1987; Adams et al., 1998). Past studies show that belonging to highly polluting sectors, push companies to disclose more non-financial information (Reverte, 2009). In this regard, the literature highlights how companies belonging to the oil, chemical or mining sectors 
provide more social and environmental information (Ness \& Mirza, 1991; Clarke \& Gibson-Sweet, 1999; Line et al., 2002; Jenkins \& Yakovleva, 2006) while companies operating in the financial sector provide more information on philanthropic actions (Clarke \& Gibson-Sweet, 1999; Line et al., 2002). In fact, the pressures that companies receive are not only connected to the size but also to the environmental impact of production (Reverte, 2009). A greater environmental impact also favours government interference in the business activity. In fact, it could intervene to protect the health and safety of the local community. Therefore, even in this case, voluntary disclosure is a tool to mitigate pressure from stakeholders, avoid government interference in business activity and reduce political costs (Ness \& Mirza, 1991; Gray et al., 1995; Adams et al., 1998; Clarke \& Gibson-Sweet, 1999). In the context of integrated reporting, greater alignment with the $<\mathrm{IR}>$ framework represents an opportunity for companies to meet the needs of stakeholders, reduce pressures and avoid government interference in business activity. In fact, as previously underlined, a greater alignment with the framework developed by the IIRC favours the standardization of contents and therefore simplifies the reading and understanding of integrated reports by stakeholders. Moreover, a greater alignment with the $<\mathrm{IR}>$ framework allows a comparison between the integrated reports of different companies and, therefore, helps stakeholders to fully understand the business dynamics. The greater knowledge of the internal dynamics of the company inevitably leads to a reduction in pressures and the possibility of intervention by the government, which represent particularly relevant aspects for companies with high environmental impacts. Therefore, in light of this, we introduce the following hypothesis:

H2: Industry environmental sensitivity is positively associated with integrated reporting alignment with the $<I R>$ framework

\section{Methodology}

\subsection{Sample}

The sample of this study is composed of 192 companies that publish an integrated report following the framework developed by the IIRC. Following Vitolla et al. (2019a) and Raimo et al. (2019), the integrated reports were selected from the "Leading Practices" and "<IR $>$ Reporters" sections of the IIRC website. This ensures that the reports are compiled in compliance with the $<\mathrm{IR}>$ framework. We have selected companies randomly. The companies in the sample are differentiated in terms of size and industry. The 2017 integrated reports were analysed in this study.

\subsection{Variables and Model Specification}

The dependent variable of this study is represented by the level of alignment with the $<\mathrm{IR}>$ framework (IRAL). The framework, developed by the IIRC, refers to two fundamental concepts and eight content elements (IIRC, 2013). These therefore represent the starting point for the development of the methodology for measuring the level of alignment. Therefore, this study evaluates the presence within the integrated report of information relating to the value creation process and the capitals that represent the fundamental concepts identified by the IIRC and information relating to organizational overview and external environment, governance, business model, risks and opportunities, strategy and resource allocation, performance, outlook and basis of presentation that represent the eight content elements identified by the IIRC. Therefore, this study analyses the presence of 10 elements represented by 2 fundamental concepts and 8 content elements. However, this study is not limited to measuring the simple presence of this information but also evaluates its nature. In fact, the alignment measure developed verifies the presence of qualitative, quantitative and monetary information for each element identified by the IIRC.

The identification of the elements and the evaluation criteria is followed by the assignment of a score. This study assigns a score of 0 in the case of absence of a single element, a score of 1 in the event that, for the single element, only qualitative information was present, a score of 2 in the event that qualitative and quantitative information was present and, finally, a score equal to 3 in the case of the presence of qualitative, quantitative and monetary information. Therefore, the maximum score for each single element is 3 and every single integrated report can assume a maximum score of alignment with the $<\mathrm{IR}>$ framework equal to 30 .

The first independent variable is represented by the firm size (SIZE). In this study, firm size is calculated as natural logarithm of total assets. The second independent variable is instead represented by the industry environmental sensitivity (IES). It is a dummy variable that assumes a value of 1 if the company operates in a highly polluting sector and a score equal to 0 in the opposite case. Following Vitolla et al. (2019a) this study considers the following sectors as environmentally sensitive: forest and paper products, automotive, logistics, aviation, metal products, chemical, mining, construction, railroad, construction materials, energy, waste management, energy utilities, water utilities and agriculture. 
In order to increase the goodness of the regression model, some control variables have been included. First of all, following Vitolla et al. (2019a) the age variable (AGE) was included. It is calculated as the number of years since the establishment of the firm up to the end of 2018. This variable represents a proxy for the stability of the company. Furthermore, this study controls for return on equity (ROE). In fact, the profitability of a company can affect the level of alignment with the $<\mathrm{IR}>$ framework. In addition, a variable related to the firm location (EU) has been added. This variable assumes a value of 1 if the company is located in Europe and a value of 0 if it is located in other continents. In a study related to integrated reporting quality, Bavagnoli et al. (2018) found that European companies provided integrated reports of higher quality than companies from other continents. Finally, an additional control variable represented by financial leverage (FINLEV) was added. Following Andrikopoulos et al. (2014), it is calculated as the ratio of the book value of debt over the book value of equity.

To test the research hypotheses, this study uses a regression model. Specifically, the model of analysis that this study proposes is reflected in the following equation:

$$
\text { IRAL }=\beta_{0}+\beta_{1} \text { SIZE }+\beta_{2} \text { IES }+\beta_{3} \text { AGE }+\beta_{4} \text { ROE }+\beta_{5} \text { EU }+\beta_{6} \text { FINLEV }+\varepsilon
$$

\section{Results}

\subsection{Descriptive Analysis and Correlation Analysis}

Table 1 provides descriptive analysis and correlation analysis. Regarding the descriptive analysis, the interesting datum is represented by the average value, equal to 22.87 , of the dependent variable, represented by the alignment with the $<\mathrm{IR}>$ framework (IRAL). Considering that the maximum obtainable score is 30 , it is clear that the analysed integrated reports have on average a high level of alignment with the indications of the IIRC.

Table 1. Descriptive statistics

\begin{tabular}{|c|c|c|c|c|c|c|c|c|c|c|c|c|}
\hline Variables & Mean & S.D. & IRA & & SIZI & & IE & & AGE & ROE & $\mathrm{EU}$ & FINLEV \\
\hline IRAL & 22.87 & 3.29 & 1 & & & & & & & & & \\
\hline SIZE & 16.64 & 2.68 & 0.390 & *** & 1 & & & & & & & \\
\hline IES & 0.32 & 0.47 & 0.160 & $* *$ & -0.081 & & 1 & & & & & \\
\hline AGE & 61.05 & 45.82 & 0.107 & & 0.181 & $* * *$ & 0.156 & $* *$ & 1 & & & \\
\hline ROE & 14.74 & 14.78 & 0.176 & $* *$ & -0.017 & & 0.098 & & -0.001 & 1 & & \\
\hline $\mathrm{EU}$ & 0.49 & 0.50 & 0.060 & & 0.146 & $* *$ & 0.199 & $* * *$ & 0.117 & $* \quad-0.044$ & 1 & \\
\hline FINLEV & 13.06 & 7.38 & 0.489 & $* * *$ & 0.326 & $* * *$ & 0.090 & & -0.029 & 0.090 & 0.103 & 1 \\
\hline
\end{tabular}

Note. $n=192$. S.D. $=$ Standard Deviation. $* * *=$ significant at the $1 \%$ level; $* *=$ significant at the $5 \%$ level; $*=$ significant at the $10 \%$ level.

Moving on to the correlation analysis, the strongest correlation is found between the dependent variable and the financial leverage (0.489). Therefore, there is no indication of an unacceptable level of multicollinearity. In fact, according to Farrar \& Glauber (1967) there are multicollinearity problems only when the coefficients exceed the values of \pm 0.8 or \pm 0.9 . Multicollinearity has also been controlled through the variance inflator factor (VIF) analysis. This analysis confirms the absence of multicollinearity since the VIFs ranged from a low value of 1.03 to a high value of 1.22 and have an average value of 1.11. Values of all VIFs below 10 allow to exclude problems related to multicollinearity (Myers, 1990).

\subsection{Results of the Hypotheses Tests}

Table 2 summarizes the results of the regression. The value of the adjusted is 0.313 , which indicates that the model can explain about $31.3 \%$ of the variance in the dependent variable. 
Table 2. Hypotheses tests

\begin{tabular}{llll}
\hline Variables & Coefficient & Standard error & p-value \\
\hline Cons & 14.578 & 1.262 & $0.000^{* * *}$ \\
SIZE & 0.320 & 0.081 & $0.000^{* * *}$ \\
IES & 0.864 & 0.438 & $0.049^{* *}$ \\
AGE & 0.003 & 0.004 & 0.459 \\
ROE & 0.025 & 0.135 & $0.058^{*}$ \\
EU & -0.365 & 0.409 & 0.374 \\
FINLEV & 0.173 & 0.028 & $0.000^{* * *}$ \\
N & 192 & & \\
Adj. $\mathrm{R}^{2}$ & 0.313 & & \\
\hline
\end{tabular}

Note. $* * *=$ significant at the $1 \%$ level; $* *=$ significant at the $5 \%$ level $; *=$ significant at the $10 \%$ level

The hypothesis 1 (H1) suggested that firm size is a determining factor of the level of compliance with what is expected by the IIRC. Specifically, the hypothesis stated that firm size positively influenced the level of alignment with the $<\mathrm{IR}>$ framework. The results show a positive and significant association between firm size (SIZE) and the level of alignment with the $<I R>$ framework (IRAL) at $p=0.000$. This result strongly supports the first hypothesis of this study and underlines how the big companies are more likely to publish integrated reports more aligned with the $<\mathrm{IR}>$ framework.

The hypothesis $2(\mathrm{H} 2)$, instead, suggested that the sector to which the company belongs was a determining factor in the level of compliance with what is expected by the IIRC. Specifically, the hypothesis stated that industry environmental sensitivity positively influenced the level of alignment with the $<\mathrm{IR}>$ framework. The results show a positive and significant association between the industry environmental sensitivity (IES) and the level of alignment with the $<\mathrm{IR}>$ framework (IRAL) at $\mathrm{p}=0.049$. This result strongly supports the second hypothesis of this study and underlines how the companies operating in highly polluting sectors are more likely to publish integrated reports more aligned with the $<\mathrm{IR}>$ framework.

With regard to the control variables, the results showed a positive impact of profitability (ROE) and financial leverage on the level of alignment with the $<\mathrm{IR}>$ framework respectively at $\mathrm{p}=0.058$ and $\mathrm{p}=0.000$.

\section{Discussion}

The results of this study clearly show first that the level of alignment of the integrated reports with the $<\mathrm{IR}>$ framework is quite high, and secondly, that firm size and industry environmental sensitivity positively impact the level of compliance. In relation to the first result, the analysed companies have therefore decided to faithfully follow the framework developed by the IIRC for the preparation of their own integrated report. The completeness and simplicity of the $<\mathrm{IR}>$ framework has certainly favoured the alignment of the reports prepared by the companies. In fact, through the guidelines and contents provided by the IIRC, companies have taken a different approach to defining strategies, according to an integrated vision, able to favor the process of creating value over time. A high level of alignment makes it possible to interconnect the various business functions and to show the relationships existing between the various capitals, the business model and the creation of value. This allows companies to provide investors and all stakeholders with an organic and complete document that is more readable and understandable. Furthermore, the alignment with the $<\mathrm{IR}>$ framework involves a standardization of reports in terms of content, which allows readers to compare different company realities. These reasons could therefore have led companies to draw up their own integrated report taking into account the provisions of the $<\mathrm{IR}>$ framework.

The greater clarity and comparability of the reports deriving from the alignment with the $<\mathrm{IR}>$ framework also explain the results obtained from the hypothesis test. The findings obtained showed that firm size and industry environmental sensitivity represent the determining factors of the level of alignment with the $<\mathrm{IR}>$ framework. Larger companies and those operating in highly polluting sectors are more exposed to pressure from stakeholders. With regards to larger companies, the greatest pressures are substantially connected to greater visibility, while for companies operating in highly polluting sectors the greater pressure is connected to the strong impact that the business activity has on the local community. For these companies, a means to reduce pressures on the part of stakeholders and to reduce the risk of government interference in corporate activity is represented by transparency. In this regard, a greater alignment of the integrated report with the framework developed by the IIRC, able to favor the standardization of contents and therefore to simplify reading and understanding by 
stakeholders, represents a means to increase transparency and, consequently, reduce pressures. Moreover, a greater alignment with the $<\mathrm{IR}>$ framework allows a comparison between the integrated reports of different companies and, therefore, helps stakeholders to fully understand the business dynamics, leading to a reduction in the pressures and risks of government interference in the business activity. These aspects can therefore explain the reason why larger companies and those operating in highly polluting sectors, exposed to greater pressures, decide to draw up their own integrated report faithfully following the $<\mathrm{IR}>$ framework.

\section{Conclusions}

To date, the level of alignment of the integrated reports with the $<\mathrm{IR}>$ framework is still a topic unexplored by the literature. Most of the previous studies focused on the adoption of this tool, on the quality, on the readability of the reports and on the amount of information contained within it, but no contribution analysed the level of compliance with the $<\mathrm{IR}>$ framework. Within this scenario, this study aimed to bridge this gap, first of all by developing a methodology for measuring the level of compliance and, secondly, by studying the factors capable of influencing the level of alignment with the $<\mathrm{IR}>$ framework.

In this regard, the results obtained show that firm size and industry environmental sensitivity positively influence the level of alignment with the $<\mathrm{IR}>$ framework.

This study contributes to the literature on integrated reporting in several ways. First of all, this study has developed a methodology for measuring the level of alignment with the $<\mathrm{IR}>$ framework that can help future researchers to carry out assessments that go beyond the simple adoption or quality of integrated reporting. This method of measuring the level of alignment with the $<\mathrm{IR}>$ framework can also be useful for companies of any size who wish to assess the level of compliance of their report with what is indicated by the IIRC. The contribution of this study is remarkable as it indicates an evaluation criterion of the integrated reports that goes beyond those already present in the literature (Pistoni et al., 2018; Pavlopoulos et al., 2019; Barth et al., 2017; Velte, 2018; Ahmed Haji \& Anifowose, 2016; Gerwanski et al., 2019).

Secondly, the results of this study increase the knowledge about the determinants of the level of alignment with the $<\mathrm{IR}>$ framework identifying two factors (firm size and industry environmental sensitivity) that have a positive effect.

The results of this study have important managerial implications. The managers of large companies and companies operating in highly polluting sectors should in fact increase transparency by developing integrated reports more in line with the $<\mathrm{IR}>$ framework to respond to the greater pressures that characterize these types of companies. The dissemination of integrated reports more in line with the $<\mathrm{IR}>$ framework, which is more clear and understandable for stakeholders, could also help companies to bridge the legitimacy gap and maintain consensus in the reference context. This consensus is a necessary condition for operational effectiveness in the current socio-economic context. However, in order to obtain this consent, it is not enough to be socially responsible but it is necessary to communicate objectives, actions and results in a clear and understandable manner.

However, this study is subject to a limitation related to the methodology. In fact, it is based on a cross-section instead of a panel analysis. This choice is due to the limited variability of the dependent variable. However, this limitation is a starting point for future studies. In fact, future studies could test the results of this study through a longitudinal analysis. Furthermore, future researchers could broaden the spectrum of determinants of the level of alignment with the $<\mathrm{IR}>$ framework, analysing the impact of other types of variables at company, country and sector level.

\section{References}

Abdullah, W. A. W., Percy, M., \& Stewart, J. (2015). Determinants of voluntary corporate governance disclosure: Evidence from Islamic banks in the Southeast Asian and the Gulf Cooperation Council regions. Journal of Contemporary Accounting \& Economics, 11(3), 262-279. https://doi.org/10.1016/j.jcae.2015.10.001

Adams, C. A., Hill, W. Y., \& Roberts, C. B. (1998). Corporate social reporting practices in Western Europe: legitimating corporate behaviour? The British Accounting Review, 30(1), 1-21. https://doi.org/10.1006/bare.1997.0060

Ahmed, H. A., \& Anifowose, M. (2016). Audit committee and integrated reporting practice: Does internal assurance matter? Managerial Auditing Journal, 31(8/9), 915-948. https://doi.org/10.1108/MAJ-12-2015-1293

Albertini, E. (2019). Integrated reporting: an exploratory study of French companies. Journal of Management 
and Governance, 23(2), 513-535. https://doi.org/10.1007/s10997-018-9428-6

Andrikopoulos, A., Samitas, A., \& Bekiaris, M. (2014). Corporate social responsibility reporting in financial institutions: Evidence from Euronext. Research in International Business and Finance, 32, 27-35. https://doi.org/10.1016/j.ribaf.2014.02.001

Barth, M. E., Cahan, S. F., Chen, L., \& Venter, E. R. (2017). The economic consequences associated with integrated report quality: capital market and real effects. Accounting, Organizations and Society, 62, 43-64. https://doi.org/10.1016/j.aos.2017.08.005

Bavagnoli, F., Songini, L., Pistoni A., \& Minutiello, V. (2018). The determinants of integrated reporting quality. an empirical analysis. EURAM Conference 2018, Reykjavik.

Bhasin, M. L., Makarov, R., \& Orazalin, N. (2012). Determinants of voluntary disclosure in the banking sector: An empirical study. International Journal of Contemporary Business Studies, 3(3), 60-71.

Busco, C., Frigo, M. L., Quattrone, P., \& Riccaboni, A. (2014). Leading practices in integrated reporting: Management accountants will guide their companies on the journey to value creation. Strategic Finance, 12(9), 23-32.

Clarke, J., \& Gibson-Sweet, M. (1999). The use of corporate social disclosures in the management of reputation and legitimacy: a cross sectorial analysis of UK Top 100 Companies. Business Ethics: A European Review, 8(1), 5-13. https://doi.org/10.1111/1467-8608.00120

Cohen, J. L. L., Holder-Webb, L. N., \& Wood, D. J. (2012). Corporate reporting on non-financial leading indicators of economic performance and Sustainability. Accounting Horizons, 26(1), 65-90. https://doi.org/10.2308/acch-50073

Coulson, A., Adams, C., Nugent, M., \& Haynes, K. (2015). Exploring metaphors of capitals and the framing of multiple capitals: challenges and opportunities for IR. Sustainability Accounting, Management \& Policy Journal, 6(3), 290-314. https://doi.org/10.1108/SAMPJ-05-2015-0032

Cowen, S. S., Ferreri, L. B., \& Parker, L. D. (1987). The impact of corporate characteristics on social responsibility disclosure: A typology and frequency-based analysis. Accounting, Organizations and society, 12(2), 111-122. https://doi.org/10.1016/0361-3682(87)90001-8

Del Sordo, C., Levy Orelli, R., \& Manes Rossi, F. (2018). Integrated reporting e valore aziendale. Integrated reporting e valore aziendale, 1-238.

Dowling, J., \& Pfeffer, J. (1975). Organizational legitimacy: Social values and organizational behavior. Pacific sociological review, 18(1), 122-136. https://doi.org/10.2307/1388226

Farrar, D. E., \& Glauber, R. R. (1967). Multicollinearity in regression analysis: the problem revisited. The Review of Economic and Statistics. 92-107. https://doi.org/10.2307/1937887

Frías-Aceituno, J. V., Rodriguez-Ariza, L., \& Garcia-Sanchez, I. M. (2013b). The role of the board in the dissemination of integrated corporate social reporting. Corporate Social Responsibility and Environmental Management, 20(4), 219-233. https://doi.org/10.1002/csr.1294

Frías-Aceituno, J. V., Rodríguez-Ariza, L., \& Garcia-Sánchez, I. M. (2014). Explanatory factors of integrated sustainability and financial reporting. Business Strategy and the Environment, 23(1), 56-72. https://doi.org/10.1002/bse. 1765

Frías-Aceituno, J. V., Rodríguez-Ariza, L., \& García-Sánchez, I. M. (2013a). Is integrated reporting determined by a country's legal system? An exploratory study. Journal of Cleaner Production, 44, 45-55. https://doi.org/10.1016/j.jclepro.2012.12.006

Gerwanski, J., Kordsachia, O., \& Velte, P. (2019). Determinants of materiality disclosure quality in integrated reporting: Empirical evidence from an international setting. Business Strategy and the Environment, 28(5), 750-770. https://doi.org/10.1002/bse.2278

Gray, R., Kouhy, R., \& Lavers, S. (1995). Corporate social and environmental reporting: a review of the literature and a longitudinal study of UK disclosure. Accounting, Auditing \& Accountability Journal, 8(2), 47-77. https://doi.org/10.1108/09513579510146996

Hackston, D., \& Milne, M. J. (1996). Some determinants of social and environmental disclosures in New Zealand companies. Accounting, Auditing \& Accountability Journal, 9(1), 77-108. https://doi.org/10.1108/09513579610109987 
IIRC. (2013). International $<$ IR $>$ Framework. Retrieved from http://www.integratedreporting.org

IIRC. (2017a). The cyclical power of integrated thinking and reporting. Retrieved from http://www.integratedreporting.org

IIRC. (2017b). Creating value-the value of human capital reporting. Retrieved from http://www.integratedreporting.org

Jenkins, H., \& Yakovleva, N. (2006). Corporate social responsibility in the mining industry: Exploring trends in social and environmental disclosure. Journal of cleaner production, 14(3-4), 271-284. https://doi.org/10.1016/j.jclepro.2004.10.004

Jensen, J. C., \& Berg, N. (2012). Determinants of traditional sustainability reporting versus integrated reporting. An institutionalist approach. Business Strategy and the Environment, 21(5), 299-316. https://doi.org/10.1002/bse.740

Khan, H. U. Z. (2010). The effect of corporate governance elements on corporate social responsibility (CSR) reporting: Empirical evidence from private commercial banks of Bangladesh. International Journal of Law and Management, 52(2), 82-109. https://doi.org/10.1108/17542431011029406

Knox, S., Maklan, S., \& French, P. (2005). Corporate social responsibility: Exploring stakeholder relationships and programme reporting across leading FTSE companies. Journal of business ethics, 61(1), 7-28. https://doi.org/10.1007/s10551-005-0303-4

Lassini, U., Lionzo, A., \& Rossignoli, F. (2016). Does business model affect accounting choices? An empirical analysis of European listed companies. Journal of Management \& Governance, 20(2), 229-260. https://doi.org/10.1007/s10997-015-9321-5

Lee, K. W., \& Yeo, G. H. H. (2016). The association between integrated reporting and firm valuation. Review of Quantitative Finance and Accounting, 47(4), 1221-1250. https://doi.org/10.1007/s11156-015-0536-y

Line, M., Hawley, H., \& Krut, R. (2002). The development of global environmental and social reporting. Corporate Environmental Strategy, 9(1), 69-78. https://doi.org/10.1016/S1066-7938(01)00159-2

Melloni, G. (2015). Intellectual capital disclosure in integrated reporting: an impression management analysis. Journal of Intellectual Capital, 16(3), 661-680. https://doi.org/10.1108/JIC-11-2014-0121

Myers, R. H. (1990). Classical and modern regression with applications. Second edition. Belmont, CA: Duxbury.

Ness, K. E., \& Mirza, A. M. (1991). Corporate social disclosure: A note on a test of agency theory. The British Accounting Review, 23(3), 211-217. https://doi.org/10.1016/0890-8389(91)90081-C

Pavlopoulos, A., Magnis, C., \& Iatridis, G. E. (2019). Integrated reporting: An accounting disclosure tool for high quality financial reporting. Research in International Business and Finance, 49, 13-40. https://doi.org/10.1016/j.ribaf.2019.02.007

Pistoni, A., Songini, L., \& Bavagnoli, F. (2018). Integrated reporting quality: an empirical analysis. Corporate Social Responsibility and Environmental Management, 25(4), 489-507. https://doi.org/10.1002/csr.1474

Raimo, N., Zito, M., \& Caragnano, A. (2019). Does national culture affect integrated reporting quality? A focus on GLOBE dimensions. In 9th International Symposium on Natural Resources Management, Zaječar, Serbia.

Reverte, C. (2009). Determinants of corporate social responsibility disclosure ratings by Spanish listed firms. Journal of business ethics, 88(2), 351-366. https://doi.org/10.1007/s10551-008-9968-9

Sharif, M., \& Rashid, K. (2014). Corporate governance and corporate social responsibility (CSR) reporting: an empirical evidence from commercial banks (CB) of Pakistan. Quality \& Quantity, 48(5), 2501-2521. https://doi.org/10.1007/s11135-013-9903-8

Sierra-García, L., Zorio-Grima, A., \& García-Benau, M. A. (2015). Stakeholder engagement, corporate social responsibility and integrated reporting: An exploratory study. Corporate Social Responsibility and Environmental Management, 22(5), 286-304. https://doi.org/10.1002/csr.1345

Simnett, R., \& Huggins, A. L. (2015). Integrated reporting and assurance: where can research add value? Sustainability Accounting, Management \& Policy Journal, 6(1), 29-53. https://doi.org/10.1108/SAMPJ-09-2014-0053

Velte, P. (2018). Is audit committee expertise connected with increased readability of integrated reports: Evidence from EU companies. Problems and Perspectives in Management, 16(2), 23-41. 
https://doi.org/10.21511/ppm.16(2).2018.03

Vitolla, F., \& Raimo, N. (2018). Adoption of integrated reporting: Reasons and benefits-A case study analysis. International Journal of Business and Management, 13(12), 244-250. https://doi.org/10.5539/ijbm.v13n12p244

Vitolla, F., Raimo, N., \& De Nuccio, E. (2018). Integrated Reporting: Development and State of Art - The Italian Case in the International Context. International Journal of Business and Management, 13(11), 233-240. https://doi.org/10.5539/ijbm.v13n11p233

Vitolla, F., Raimo, N., \& Rubino, M. (2019b). Intellectual Capital Disclosure and Firm Performance: An Empirical Analysis through Integrated Reporting. In 7th International OFEL Conference, Dubrovnik, Croatia.

Vitolla, F., Raimo, N., \& Rubino, M. (2019c). Appreciations, criticisms, determinants, and effects of integrated reporting: A systematic literature review. Corporate Social Responsibility and Environmental Management, 26(2), 518-528. https://doi.org/10.1002/csr.1734

Vitolla, F., Raimo, N., Rubino, M., \& Garzoni, A. (2019a). The impact of national culture on integrated reporting quality. A stakeholder theory approach. Business Strategy and the Environment. https://doi.org/10.1002/bse.2332

Vitolla, F., Raimo, N., Rubino, M., \& Garzoni, A. (2019d). How pressure from stakeholders affects integrated reporting quality. Corporate Social Responsibility and Environmental Management. https://oi.org/10.1002/csr.1850

Vitolla, F., Salvi, A., Raimo, N., Petruzzella, F., \& Rubino, M. (2019e). The impact on the cost of equity capital in the effects of integrated reporting quality. Business Strategy and the Environment. https://doi.org/10.1002/bse.2384

Watts, R., \& Zimmerman, J. (1986). Positive Accounting Theory. Prentice Hall, Englewood Cliffs, NJ.

Wyatt, A. (2008). What financial and non-financial information on intangibles is value-relevant? A review of evidence. Accounting and Business Research, 38(3), 217-256. https://doi.org/10.1080/00014788.2008.9663336

\section{Copyrights}

Copyright for this article is retained by the author(s), with first publication rights granted to the journal.

This is an open-access article distributed under the terms and conditions of the Creative Commons Attribution license (http://creativecommons.org/licenses/by/4.0/). 